$\begin{array}{lll}\text { УдК 616-089.5+618.1-089 DOI 10.31640/3-4.2018(22) } & \text { Поступила 04.10.2016 }\end{array}$

О. Н. ЮРЧЕНКО (Харьков)

\title{
КОМБИНИРОВАННАЯ ВНУТРИВЕННАЯ АНЕСТЕЗИЯ В ОПЕРАТИВНОЙ ГИНЕКОЛОГИИ ОДНОГО ДНЯ
}

Отделение анестезиологии с койками для интенсивной терапии ГУ «Институт медицинской радиологии им. С. П. Григорьева НАМН Украины»<olge.yurchenko@gmail.com>

\begin{abstract}
Для современной женщины в ежеминутно ускоряющемся темпе жизни всё бо́льшую популярность приобретает гинекология «одного дня». Многие пащиентки прибегают к её помощи с диагностической и лечебной иелью, поскольку она даёт возможность следить за женским здоровьем, избегая длительного отлучения от дел. В статье доказана эффективность использования противовоспалительных нестероидых средств в качестве дополнительной аналгезии при выскабливании полостии матки и уменьшении интраоперачионной дозы наркотических аналгетиков. Такая медикаментозная комбиначия сокращает время послеоперащионного пробуждения. Становится возможным достижение необходимого уровня угнетения сознания с достаточным аналгетическим эффектом при использовании меньшей дозы наркотических препаратов и прекурсоров. Предложенная медикаментозная комбиначия соответствует современным требованям амбулаторной анестезии, в частности блокирование болевого ощущения во время процедуры, отсутствие эффекта присутствия при оперативном вмешательстве, сохранение адекватной дыхательной функции, отсутствие выраженного кардиодепрессивного действия, возможность перевода пащиентки из операщионной в общую палату, минуя отделение интенсивной терапии. Сокращается время послеоперащионного пребывания пациенток в отделении. Количество осложнений не увеличивается.
\end{abstract}

Ключевые слова: пропофол, кетамин, ненаркотические аналгетики, амбулаторная гинекология.

Введение. В настоящее время - век технического прогресса, интенсивного укрепления коммерческого и производственного секторов - тепмы жизни стремительно увеличиваются. Безусловно, столь высокий подъём уровня мирового развития устанавливает перед населением достаточно жёсткие временные рамки. Для создания прочного фундамента экономической деятельности, увеличения доходов возникла необходимость в ещё более длительных временных инвестициях. Границы гендерных различий в бизнесе стираются. В современном экономическом мире права женщины сравнялись с таковыми мужчины. Теперь представительницы слабого пола не имеют возможности уделять своему женскому здоровью достаточно времени. В связи с этим гинекология «одного дня» получает всё большее признание.

Такой подход к выявлению и контролю за заболеваниями женской половой сферы зарекомендовал себя как эффективный, быстрый, надёжный способ диагностики и лечения патологии половых органов. Однако даже виртуозное проведения малых гинекологических оперативных вмешательств невозможно без надлежащего анестезиологического пособия. Появление на фармакологическом рынке новых препаратов анестезиологического ряда сделало возможным фактическое воплощение в жизнь термина «гинекология одного дня». Отсутствие длительного депрессивного действия на витальные функции организма даёт возможность раннему восстановлению сознания, постоперационной, адаптации и активизации пациенток. При этом сохраняются необходимые качества амбулаторной анестезии: купирование болевых ощущений во время процедуры, отсутствие эффекта присутствия при оперативном вмешательстве, сохрание адекватной дыхательной функции, отсутствие выраженного кардиодепрессивного действия, возможность перевода пациентки из операционной в общую палату, а не в отделение интенсивной терапии.

Цель исследования - разработать комбинацию фармакологических препаратов для комбинированной внутривенной анестезии с сокращённым временем пробуждения пациенток при малых гинекологических операциях. 
Задачи - включение в премедикацию анестезиологического сопровождения малых гинекологических оперций нестероидных противовоспалительных средств с целью дополнительной аналгезии.

Материалы и методы. В период с 08.2015 г. по 06.2016 г. на базе ГУ «ИМР им. С. П. Григорьева НАМН Украины» с диагностической и лечебной целью проведено 33 малых гинекологических оперативных вмешательства: из них 13 полипэктомии и 20 диагностических выскабливаний полости матки. Возраст пациенток составил от 28 до 69 лет. Все вмешательства проводили в условиях медикаментозной седации/комбинированной внутривенной анестезии с сохранённым спонтанным дыханием.

Пациенткам катетеризировали кубитальную вену, за 20 мин до оперативного вмешательства проводили внутривенную премедикацию, включающую метоклопрамид по 2 мг и атропина сульфата из расчёта 0,1 мг/кг. При проведении анестезиологического сопровождения все пациентки после подписания добровольного информированного согласия были разделены на три группы: I - 11 женщин, которым проводили медикаментозную моноседацию пропрофолом в дозе 2,5-3 мг/кг; II - 11 женщин, которым анестезиологическое обеспечение проводили комбинацией пропофола в дозе 2,5 мг/кг и кетамина 3 мг/кг; III - 11 пациенток, дополнительно получавших в премедикационном комплексе за 20 мин до операции нестероидное противовоспалительное средство декскетопрофена трометамол 2,5 \% 2 мл внутривенно. Анестезию обеспечивали использованием аналогичной фармакологической схемы II группы больных. Препараты вводили через внутривенный катетер, медленной струйной инфузией, которая прекращалась при достижении клинического эффекта или продлевали её до его наступления.

Результаты и их обсуждение. Медикаментозный сон во всех трёх группах наступал одинаково быстро без психомоторного возбуждения. Вмешательство начинали сразу после выключения сознания и снижения произвольного тонуса мышц. В течение операции пациентки I и II групп нуждались в дополнительном введении гипнотической комбинации. Суммарная доза пропофола после дополнительных интраоперационных инфузий в I группе составила 4,5-5 мг/кг; во II группе пропофола 2-2,5 мг/кг и кетамина 3 мг/кг. Пациентки III группы нуждались в наиболее низких дозах анестезиологических препаратов. Для обеспечения анестезиологического пособия в этой части выборки требовалось около 1,5 мг/кг пропофола и 2 мг/кг кетамина.

Для ускорения пробуджения пациенток II и III групп окликали по имени, просили открыть глаза, легко пошлёпывали по щеке. Пробуждение пациенток I группы проходило плавно. Ориентация во времени и месте восстанавливалась на 4-5-й минуте после начала пробуждения. Перевод в общую палату был возможен на 11-й мин.

Больные II и III групп просыпались достаточно быстро, без психомоторного возбуждения. Послеоперационное пробуждение женщин, не получавших декскетопрофен, наступило на 4-5-й минуте. Их перевод в палату осуществлён на 10-й минуте.

Пациентки III группы пробуждались практически сразу после окончания оперативного вмешательства: 2 женщины проснулись самостоятельно и уже через 2 мин после пробуждения могли чётко ответить на вопросы, касающиеся их личности, времени и места; 3 из 11 проснулись после их оклика по имени, у 4 женщин пробуждение наступило после лёгкого пошлёпывания по щеке, 2 женщины проснулись на 2-й минуте после оклика и пошлёпывания. Перевод в палату был возможен на 5-6-й минуте.

У 2 пациенткок I группы интраоперационно наблюдалась побочная аллергическая реакция в виде ларингоспазма, которая была немедленно купирована введением 12 мг дексаметазона внутривенно.

Больные либо после пробуждения отмечали яркие, приятные, красочные сны, либо сновидений не помнили. Кошмарные сновидения, болевые ощущения, эффект присутствия во время операции никто из пациенток не отмечал. 
Суммарная доза пропофола после превентивной аналгезии декскетопрофеном в сравнении с монокомпонентной интраоперационной седацией снизилась на 70 \% по сравнению с бикомпонентной анестезией пропофолом и кетамином - на $40 \%$.

Время послеоперативного пробуждения пациенток, дополнительно получавших в составе премедикации декскетопрофен, сократилось на 62 \% по сравнению с пациентками, получавшими как аналгетический компонент гипнотик с незначительным аналгетическим компонентом (пропофол). Аналогичное время у больных, получавших комбинацию гипнотических препаратов с увеличенным аналгетическим эффектом, за счёт кетамина достоверно не отличалось от такового в контрольной группе.

Выводы. Таким образом, можно сделать вывод, что дополнительное превентивное введение нестероидных противовоспалительных средств (декскетапрофена) на этапе премедикации у пациенток, которым показана малая гинекологическая операция, достоверно сокращает время послеоперационного пробуждения, снижая необходимые для достижения клинического эффекта дозировки препаратов для наркоза. в том числе и наркотического ряда, путём усиления аналгетического компонента последних. Появляется возможность достижения необходимого уровня выключения сознания при использовании менее низких доз нарокотических препаратов и прекурсоров. Предложенная комбинация сохраняет соблюдение требований к амбулаторной анестезии: купирование болевых ощущений во время процедуры, отсутствие «эффекта присутствия» при оперативном вмешательстве, сохранение адекватной дыхательной функции, отсутствие выраженного кардиодепрессивного действия, возможность перевода пациентки из операционной в общую палату, а не в отделение интенсивной терапии. Сокращается время послеоперационного пребывания пациенток в отделении. Количество осложнений не увеличивается.

$$
\text { Спи сок ли те рат уры }
$$

1. Гельфанда Б. Р. Анестезиология и интенсивная терапия: Практ. руководство / Под ред. проф. Б. Р. Гельфанда. - М.: Литтерра, 2006. $-576 \mathrm{c}$.

2. Женило В. М., Овсянняков В. Г., Белявский П. А. Основы современной общей анестезии. - Р. Дону: Феникс, 1998. $347 \mathrm{c}$.

3. Жилка Н. Я. Стан надання хірургічної допомоги в Україні. Шляхи вирішення проблем // Зб. наук. праць асоціації гінекологів України. -К.: Інтермед, 2004. C. $167-174$.

4. Кати Н., Ферранте Ф. М. Послеоперационная боль / Под ред. F. M. Ferrante, TJR. Vade Boncouer: Пер. с англ. - М., 1998. $619 \mathrm{c}$.

5. Пфеннинг Е. Материалы симпозиума «Два десятилетия применения кетамина». Берлин, 1998. - С. 5-20.

6. Смит Й., Уайт П. Тотальная внутривенная анестезия: Пер. с. англ. - М. - СПб: ЗАО «Изд-во БИНОМ - Невский диалект», 2002. - $172 \mathrm{c}$.

7. Kehlet $H$. Labat lecture 2005. Surgical stress and postoperative outcome from here to where? // Reg. Anaesth. Pain. Med. -2006. - Vol. 31. - S. 47-52.
1. Gel'fanda B. R. Anesteziologiya i intensivnaya terapiya: Prakt. rukovodstvo / Pod red. prof. B. R. Gel'fanda. - M.: Litterra, 2006. $576 \mathrm{~s}$.

2. Zhenilo V. M., Ovsyannyakov V. G., Belyavskij P. A. Osnovy sovremennoj obshchej anestezii. - R. Donu: Feniks, 1998. - 347 s.

3. Zhilka N. Ya. Stan nadannya hirurgichnoï dopomogi v Ukraïni. SHlyahi virishennya problem // Zb. nauk. prac' asociacii ginekologiv Ukraïni. -K.: Intermed, 2004. - S. 167-174.

4. Katc N., Ferrante F. M. Posleoperacionnaya bol' / Pod red. F. M. Ferrante, TJR.Vade Boncouer: Per. s angl. - M., 1998. - 619 s.

5. Pfenning E. Materialy simpoziuma «Dva desyatiletiya primeneniya ketamina». - Berlin, 1998. - S. 5-20.

6. SmitJ., Uajt P. Total'naya vnutrivennaya anesteziya: Per. s. angl. - M. - SPb: ZAO «Izdvo BINOM - Nevskij dialekt», 2002. - $172 \mathrm{~s}$. 


\section{КОМБІНОВАНА ВНУТРІШНЬОВЕННА АНЕСТЕЗІЯ В ОПЕРАТИВНІЙ ГІНЕКОЛОГІЇ ОДНОГО ДНЯ}

\section{О. Н. Юрченко (Харків)}

Для сучасної жінки, у темпі життя який щохвилинно пришвидшується, все більшої популярності набуває гінекологія «одного дня». Багато пацієнток вдаються до iï допомоги 3 діагностичною та лікувальною метою, оскільки вона дає можливість нагляду за жіночим здоров'ям уникаючи тривалого відлучення від справ. У статті доведено ефективність використання протизапальних нестероїдних засобів в якості до даткової аналгезії вишкрібання порожнини матки і зменшення інтраопераційної дози наркотичних анальгетиків. Така медикаментозна комбінація скорочує час післяопераційного пробудження хворих. Стає можливим досягнення необхідного рівня блокування свідомості із достатнім аналгетичним ефектом при використаннні меньшої дози наркотичних препаратів на прекурсорів. Запропонована медикаментична комбінація збергає дотримання вимог до амбулаторної анестезіології а саме: купування больових відчуттів під час процедури, відсутність ефекту присутності при оперативному втручанні, збереження адекватної дихальної функції, відсутність вираженої кардіодепресивної дії, можливість перевода пацієнтки до загальної палати уникаючи відділення інтенсивної терапії. Скорочується час післяопераційного перебування пацєнток у відділенні. Кількість ускладнень не збільшується.

Ключові слова: пропофол, кетамін, ненаркотичні аналгетики, амбулаторна анестезіологія.

\section{COMBINED INTRAVENOUS ANESTESIA IN OUTPATIENT OPERATIV GYNECOLOGY}

O. M. Yurchenko (Kharkiv, Ukraine)

«Grigoriev's Institute for Medical Radiology of National Academy of Medical Science of Ukraine», critical care department

For the modern woman in continually accelerating rhythm of life, outpatient gynecology becomes more popular. Many patients use it with diagnostic and therapeutic purposes, because it makes possible to monitor women's health with avoiding prolonged absence at work. In this article, effectiveness of inclusion of nonsteroidal anti-inflammatory agents for the purpose of additional analgesia of uterus curettage and reduction of intraoperative doses of hypnotic drugs. The proposed combination of the drug retains compliance to the ambulatory anaesthesia, such as relief of pain during the procedure, absence of the effect of the presence at the surgical operation, maintenance of adequate respiratory function, absence of the cardiodepressive action, the possibility of transferring of the patient from the operating room to a general regimen ward without the intensive care unit. The time of postoperative stay of patients in the department is reduced. The number of complications is not increased.

Key words: propofol, ketamine, non-drugs analgesics, outpatient gynecology.

\section{ОЦІНКА КОНЦЕНТРАЦІЇ ОКСИДУ АЗОТУ В КРОВІ ЯК МАРКЕРА ГЕСТАЦІЙНОЇ ЕНДОТЕЛІАЛЬНОЇ ДИСФУНКЦЇ̈}

Кафедра акушерства та гінекології 1 (зав. - проф. Л. М. Маланчук) ДВНЗ «Тернопільський державний медичний університет ім. І. Я. Горбачевського МОЗ України»<galina_nysa@mail.ru>

Стаття присвячена визначенню концентрації оксиду азоту в крові вагітних із синдромом втрати плода та без репродуктивних втрат. Статистична обробка отриманих даних проведена за програмою Exсеl 2010. Після визначення кониентращї нітровмісних сполук у водопровідній воді оцінювали вміст активних метаболітів оксиду азоту в сироватиі крові за методом П. П. Голікова та Н. Ю. Ніколаєвої. Встановлено, що середня концентрація оксиду азоту в сироватиі крові вагітних із синдромом втрати плода знижена порівняно з жінками без репродуктивних втрат. Як медикаментозну корекцію призначали донатор оксиду азоту - сироп L-аргініну аспартату - по 5 мл 3 рази на добу рег оs протягом 14 днів. Після проведеної терапї показники середньої конщентра- 